\title{
A study of histomorphology and immunohistochemistry of papillary squamotransitional cell carcinoma: A rare variant of squamous cell carcinoma of cervix
}

\author{
Avani Tiwari ${ }^{1}$, Harendra Kumar ${ }^{2}$, Ajay Singh Thakur ${ }^{1}$, Amit Choraria ${ }^{3}$, \\ Vivek Choudhary ${ }^{4}$ \\ ${ }^{\prime}$ Department of Pathology, Regional Cancer Centre, Pt. JawaharLal Nehru Medical College, Raipur, India \\ ${ }^{2}$ Sarojini Naidu Medical College, Agra, India \\ ${ }^{3}$ Department of Surgical Oncology, Regional Cancer Centre, Pt. JawaharLal Nehru Medical College, Raipur, India \\ ${ }^{4}$ Department of Radiotherapy, Regional Cancer Centre, Pt. JawaharLal Nehru Medical College, Raipur, India
}

\author{
Keywords: \\ Cervix; \\ Cytokeratin; \\ CK 20; \\ Papillary \\ squamotransitional cell \\ carcinoma;
}

\begin{abstract}
Background: Papillary squamotransitional cell carcinoma is a histopathological subcategory of squamous cell carcinoma of the uterine cervix that often resembles transitional cell carcinoma of the urinary tract. Histologically, it can be misdiagnosed as transitional cell carcinoma or other papillary lesions of the cervix. Stromal invasion on biopsy is difficult to diagnose due to the exophytic papillary growth of the tumor. It also has a propensity for local recurrence and late metastasis. The study is performed to diagnose and categorize this uncommon variant of carcinoma cervix.
\end{abstract}

Materials and Methods: Eighteen cases of Papillary squamotransitional cell carcinoma were diagnosed on a punch biopsy specimen on routine hematoxylin and eosin-stained sections. The tumors were categorized into three groups according to the percentage of squamous and transitional components. Further, immunohistochemical evaluation for cytokeratin 7 and cytokeratin 20 was done.

Results: The mean age of the patients was 51.61 years (range 37-62 years). The most common clinical presentation was postmenopausal bleeding. All the cases showed papillary architecture with fibrovascular cores. The papillae were lined by three cell types: clear, intermediate, and basaloid. Stromal invasion was seen in all the cases. All the cases showed positive immunostaining for cytokeratin 7 and negative immunostaining for cytokeratin 20 .

Conclusion: Papillary squamotransitional cell carcinoma deserves accurate pre-operative biopsy diagnosis due to the risk of misdiagnosis as benign papillary or malignant transitional lesions. Immunohistochemistry plays an important role in the diagnosis of these tumors and is recommended in every case. Late recurrence and metastasis warrants a longer duration of follow up.

\section{Correspondence:}

Dr. Avani Tiwari

Assistant Professor, Department of Pathology

Regional Cancer Centre, Pt. JawaharLal Nehru Medical College, Raipur,

India

ORCID ID: 0000-0002-2890-7857

Email: dravanitiwari80@gmail.com

Received : November $10^{\text {th }} 2020$; Accepted : January 17 2021

Citation: Tiwari A, Kumar H, Thakur AS, Choraria A, Choudhary V. A study of histomorphology and immunohistochemistry of papillary squamotransitional cell carcinoma: A rare variant of squamous cell carcinoma of cervix. J Pathol Nep 2021;11: 1811-7.DOI: 10.3126/jpn.v11i1.32820

Copyright: This is an open-access article distributed under the terms of the Creative Commons Attribution 4.0 International License, which permits unrestricted use, distribution, and reproduction in any medium, provided the original author and source are credited.

\section{INTRODUCTION}

Cervical carcinoma is the third most common cancer in women worldwide and the second most common cancer in the developing world, with about 5,30,000 new cases each year resulting in 2,75,000 deaths globally. ${ }^{1}$ The average age at diagnosis is 45 years. ${ }^{2}$ Squamous cell carcinoma (SCC) is the most common histopathologic type, accounting for $90 \%$ of all carcinoma cervix cases. The two most common variants of SCC are large cell keratinizing SCC and large cell nonkeratinizing SCC. Various less common variants have been described and include small cell SCC, papillary 
squamotransitional cell carcinoma (PSTCC), verrucous carcinoma, and sarcomatoid SCC. ${ }^{2}$

PSTCC of the uterine cervix is a distinct clinicopathological subtype of cervical cancer. ${ }^{3}$ It has been reported to represent $1.6 \%$ of all cervical cancers. ${ }^{4}$ It often resembles transitional cell carcinoma (TCC) of the urinary tract. ${ }^{5}$ It has been described at other sites of the female genital tract like the ovary and vagina ${ }^{6,7}$ and was initially designated as "transitional cell carcinoma" by Albores-Saavedra and Young. ${ }^{8}$ However, due to its distinct clinical behavior it should be distinguished from other TCC and other papillary lesions of the cervix, including condyloma, squamous papilloma, verrucous carcinoma, and cervical intraepithelial neoplasia grade 3 with papillary configuration. ${ }^{9-12}$

PSTCC grossly has a distinguishing surface papillary growth pattern and can be deeply invading. Histologically, it is characterized by sheets of atypical basaloid cells, often non-keratinizing, showing moderate to severe nuclear atypia, and supported by fibrovascular cores. ${ }^{10,11}$ It shows aggressive biological behavior and needs close and extended follow up after definitive treatment as it tends to recur locally and can have late metastasis. ${ }^{12-15}$ We herein present a study of detailed histomorphology along with immunohistochemistry (IHC) correlation of 18 cases of PSTCC diagnosed in our institution.

\section{MATERIAL AND METHODS}

This was an observational study and all 18 cases were reported in the Department of Pathology, Regional Cancer Centre, Pt. JawaharLal Nehru Medical College, India. The material obtained was cervical punch biopsy in 17 cases and vaginal vault biopsy in one case (recurrence). Hematoxylin and Eosin (H\&E) stained sections were reported by one pathologist and reviewed separately by another pathologist. Other tumors like SCC without a papillary pattern, verrucous carcinomas, papillary adenocarcinomas, squamous papillomas, and condyloma accuminata were excluded from the study.

A definitive set of detailed histomorphological features; papillae formation, fibrovascular cores, cell types, the presence of atypia/mitosis, stromal invasion and infiltration, inflammatory response were assessed in each case. The semiquantitative assessment of relative amounts of squamous and transitional areas in each tumor was done in both the noninvasive papillary and the invasive areas. Histomorphologically the tumors were categorized into three groups; SCC group (typical squamous appearance in $>90 \%$ of the tumor), TCC group (typical transitionallike appearance in $>90 \%$ of the tumor), and PSTCC group (features intermediate between the above two morphologic extremes). Relevant clinical information about treatment and follow-up was obtained from the patient's hospital records. IHC was performed on formalin-fixed paraffin sections of each tumor using a manual polymer detection system with heat-induced epitope retrieval. The following pre-diluted, ready to use, primary antibodies were used: cytokeratin7 (CK7) (clone OVTL; Biogenex), cytokeratin20 (CK20) (clone EPR1622Y; Biogenex). Immunoreactivity for CK7 and CK20 was quantitatively assessed in each case by estimating the percentage of cells showing membrane staining, and scoring the intensity of staining as $0,1+, 2$ + , or $3+$ according to the $\mathrm{H}$-scoring system.16 If at least $5 \%$ of the cells displayed at least $1+$ intensity, the case was considered positive.

\section{RESULTS}

The mean age of the study population was 51.61 years with a range between 37 and 62 years. 16 out of 18 women were postmenopausal. The presenting symptoms included postmenopausal bleeding (11 cases), foul-smelling excessive white discharge (4 cases), metrorrhagia ( 2 cases), and pain in the lower abdomen (1 case). Other associated systemic complaints were weight loss, fever, and dysuria. One patient had a history of total abdominal hysterectomy for carcinoma cervix 10 years back. None of the patients had a history of prior, recurrent, or subsequent transitional cell carcinoma of the urinary tract. Local examination in almost all the cases revealed bulky, friable, ulcero-proliferative and/or ulcero-infiltrative masses involving the cervix and vaginal vault ( 1 case). Histopathological examination of all the 18 cases is illustrated in Table 1 .

All 18 cases showed papillary architecture with fibrovascular cores (fig. 1a). In addition, 2 cases showed the presence of additional micropapillae without fibrovascular core (fig. 1f). The papillae were lined by multilayered atypical epithelial cells showing variable but significant cytologic atypia. The epithelium lining the papillae resembled that of the highgrade squamous intraepithelial lesion (HSIL) of the cervix with transitional differentiation (Figure 1b). The squamous component was identified by the presence of eosinophilic glassy cytoplasm, intercellular bridges, and keratin pearls. All 18 cases included in the study fell into the category of PSTCC with the squamous component ranging from $10-35 \%$. The predominant lining cell type found in all the cases was intermediate cells having a moderate amount of eosinophilic cytoplasm, hyperchromatic to vesicular nuclei with prominent nucleoli (fig. 1b). Other cell types were clear cells showing abundant clear cytoplasm, vesicular nuclei with prominent nucleoli, and the basaloid cells having a high $\mathrm{N}$ : $\mathrm{C}$ ratio, scant cytoplasm, and hyperchromatic nuclei ( 4 cases each; fig. 1e and $1 \mathrm{~b}$ ). Nuclear atypia was moderate in the majority of the cases (15 in number) and severe in 3 cases (fig. 1d). Severe atypia was identified by the presence of a high $\mathrm{N}: \mathrm{C}$ ratio, marked pleomorphism and anisonucleosis, and hyperchromasia. Multinucleated giant cells, as well as bizarre cells, were seen in 2 cases 
Table 1: IHC results with Antibodies specific to E746-A750 exon 19 deletion and L858R exon 21 mutation

\begin{tabular}{|c|c|c|c|c|c|c|c|c|c|}
\hline No. & Papilla & $\begin{array}{c}\text { Fibrovascular } \\
\text { core }\end{array}$ & Cell type & Nuclear atypia & $\begin{array}{c}\text { Mitotic figures } \\
/ 10 \mathrm{hpf}\end{array}$ & $\begin{array}{c}\% \text { of squamous } \\
\text { component }\end{array}$ & $\begin{array}{l}\text { Stromal } \\
\text { invasion }\end{array}$ & Inflammation & Other features \\
\hline 1 & + & + & Intermediate & Moderate & $6-7$ & $20-25$ & + & Acute+chronic & Keratin pearls \\
\hline 2 & + & + & Intermediate, clear & Moderate & $4-5$ & $20-25$ & + & Chronic & Necrosis \\
\hline 3 & + & + & Intermediate & Moderate & $2-3$ & $10-15$ & + & Chronic & Calcification \\
\hline 4 & + & + & Intermediate, basal & Moderate & $2-3$ & $25-30$ & + & Chronic & - \\
\hline 5 & + & + & Intermediate & Moderate & $2-3$ & $30-35$ & + & Acute + chronic & $\begin{array}{l}\text { Koilocytosis, } \\
\text { keratin pearls }\end{array}$ \\
\hline 6 & + & + & Intermediate & Moderate & $5-7$ & $25-30$ & + & Acute+chronic & Necrosis \\
\hline 7 & + & + & Intermediate & Severe & $8-10$ & $30-35$ & + & Acute + chronic & $\begin{array}{c}\text { Giant } \& \text { bizarre } \\
\text { cells }\end{array}$ \\
\hline 8 & + & + & Intermediate, basal & Moderate & $10-12$ & $10-15$ & + & Acute+chronic & Necrosis, LVI \\
\hline 9 & + & + & Intermediate & Moderate & $3-5$ & $15-20$ & + & Acute+chronic & Micropapillae \\
\hline 10 & + & + & Intermediate,clear & Moderate & $5-7$ & $10-15$ & + & Acute + chronic & Necrosis \\
\hline 11 & + & + & Intermediate,clear & Moderate & $2-3$ & $10-15$ & + & Chronic & Micropapillae \\
\hline 12 & + & + & Intermediate & Severe & $6-8$ & $15-20$ & + & Acute+chronic & - \\
\hline 13 & + & + & Intermediate, clear & Severe & $8-10$ & $10-15$ & + & Acute+chronic & $\begin{array}{c}\text { Giant \& bizarre } \\
\text { cells }\end{array}$ \\
\hline 14 & + & + & Intermediate, basal & Moderate & $4-6$ & $20-25$ & + & Acute+chronic & - \\
\hline 15 & + & + & Intermediate, basal & Moderate & $6-8$ & $10-15$ & + & Acute+chronic & - \\
\hline 16 & + & + & Intermediate & Moderate & $5-7$ & $20-25$ & + & Acute+chronic & Koilocytosis \\
\hline 17 & + & + & Intermediate & Moderate & $5-7$ & $20-25$ & + & Chronic & Keratin pearls \\
\hline 18 & + & + & Intermediate & Moderate & $4-6$ & $10-15$ & + & Chronic & Necrosis \\
\hline
\end{tabular}

HPF- high power field, LVI- lymphovascular invasion

\begin{tabular}{|c|c|c|c|c|}
\hline & \multicolumn{2}{|c|}{ CK 7} & \multicolumn{2}{|c|}{ CK 20} \\
\hline & $\%$ of cells & $\begin{array}{l}\text { Intensity of } \\
\text { staining }\end{array}$ & $\%$ of cells & $\begin{array}{l}\text { Intensity of } \\
\text { staining }\end{array}$ \\
\hline 1 & $30-40$ & $2+$ & 0 & - \\
\hline 2 & $20-30$ & $2-3+$ & 0 & - \\
\hline 3 & $60-70$ & $2-3+$ & 0 & - \\
\hline 4 & $50-60$ & $2+$ & 0 & - \\
\hline 5 & $40-50$ & $2+$ & 0 & - \\
\hline 6 & $30-40$ & $2-3+$ & 0 & - \\
\hline 7 & $70-80$ & $2+$ & 0 & - \\
\hline 8 & $70-80$ & $2+$ & 0 & - \\
\hline 9 & $15-20$ & $2-3+$ & 0 & - \\
\hline 10 & $70-78$ & $2+$ & 0 & - \\
\hline 11 & $50-60$ & $2+$ & 0 & - \\
\hline 12 & $40-50$ & $3+$ & 0 & - \\
\hline 13 & $20-25$ & $2+$ & 0 & - \\
\hline 14 & $80-90$ & $2+$ & 0 & - \\
\hline 15 & $80-90$ & $2+$ & 0 & - \\
\hline 16 & $20-30$ & $1-2+$ & 0 & - \\
\hline 17 & $20-30$ & $1-2+$ & 0 & - \\
\hline 18 & $40-50$ & $2+$ & 0 & - \\
\hline
\end{tabular}

(fig. 1d). Mitosis ranged from 2-3 to 10-12/high power field including atypical mitotic figures (fig. 1d; inset). Definitive evidence of stromal invasion in the form of nests, fronds, and sheets surrounded by chronic inflammatory cells was seen in all 18 cases $(100 \%)$. Two cases were reported as
HSIL initially and on subsequent deeper biopsy, revealed the presence of invasive PSTCC. Additional findings were necrosis in 5 cases and HPV related koilocytic changes in 2 cases. The stroma in most of the cases showed acute and chronic inflammatory infiltrates. All the cases showed positive immunostaining for CK7 (fig. 2a) and negative immunostaining for CK20 (fig. 2b) Table-2.

\section{DISCUSSION}

Non-glandular papillary carcinoma of the uterine cervix with transitional or squamous differentiation is a rare tumor that often resembles TCC of the urinary tract. ${ }^{5,9}$ They were poorly characterized in the literature and it remained unclear for a long time whether these tumors represented a different group of tumors or were within a spectrum of clinically homogenous and morphologically similar entities. ${ }^{15,17}$ Marsh, in the year 1952 initially identified these lesions when 3 out of 31 papillary tumors of the cervix turned out to be malignant. Later in 1958, Kazal observed that 2 out of 20 cases reported as squamous cell papillomas of the cervix showed transformation to SCC. ${ }^{18}$ Similar to the above study, Qizilbash in the year 1974 also found 2 of the 21 papillary squamous tumors of the cervix as malignant, although he interpreted them as verrucous carcinomas. ${ }^{5}$ It was Randall et al in the year 1986 who first described these tumors as histologically distinctive cervical malignant tumors with a spectrum of in-situ to invasive forms. They provided the criteria for distinguishing PSTCC from benign papillary squamous lesions and verrucous carcinomas. ${ }^{4}$ The Armed Forces Institute of Pathology fascicle used the terms 


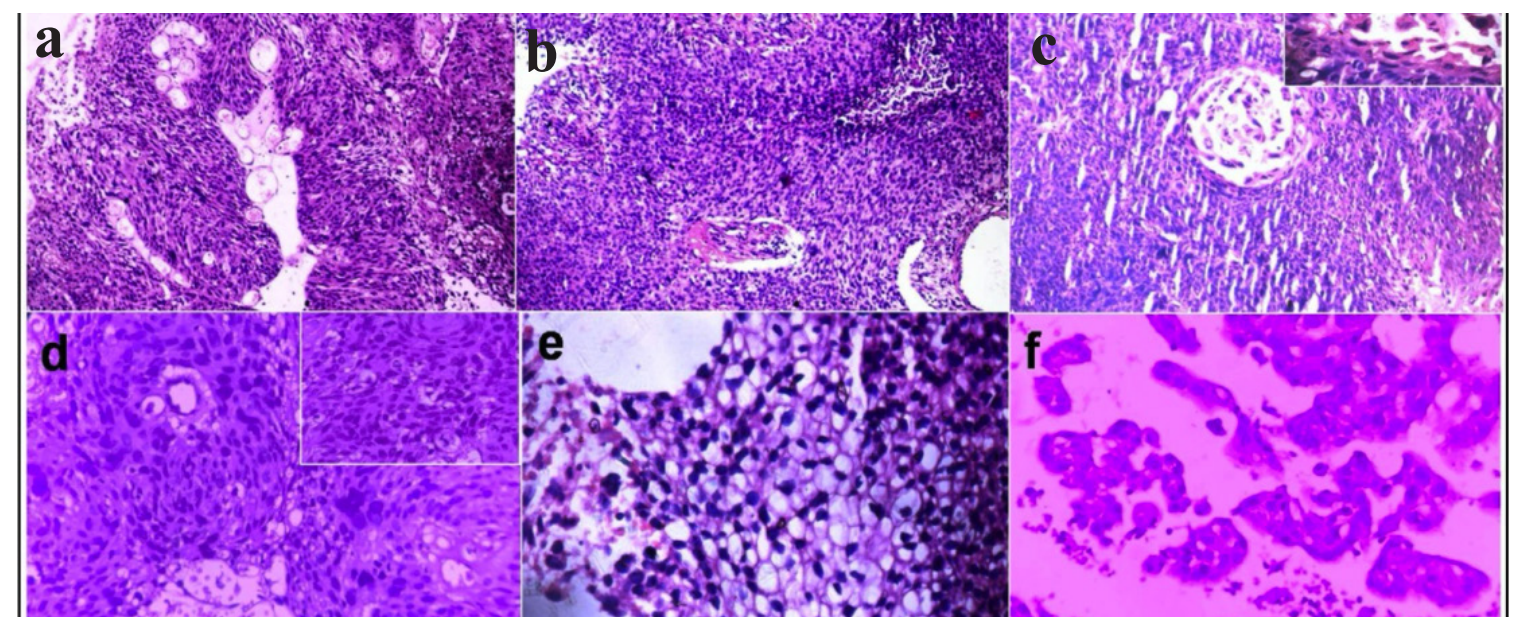

Figure 1: a) Prominent papillary architecture with fibrovascular cores (H\&E; 100X). b) Typical papillary squamotransitional area with papillae lined by central basaloid and peripheral intermediate cells $(H \& E ; 100 X)$. c) Areas of extracellular keratinization along with dyskeratotic squamous epithelial cells (H\&E; 100X); Inset (H\&E 400X). d) Prominent nuclear pleomorphism and multinucleated giant cells (H\&E; 400X); Inset: Atypical mitotic figures (H\&E, 400X). e) Clear cell areas (H\&E; 400X).f) Micropapillary architecture (H\&E; 400X)

"squamous" and "transitional" interchangeably to refer to these papillary carcinomas of the cervix., ${ }^{9} 19$ Koenig et al in 1996 suggested that these tumors can be divided into three groups based on their histologic appearance: Predominantly squamous, predominantly transitional, and mixed squamous and transitional..$^{5}$ Finally, in the year 2003 WHO designated squamotransitional like carcinoma as a subcategory of the epithelial squamous tumors of the uterine cervix. ${ }^{20}$

Literature reveals varied reports regarding the etiology of PSTCC. $2,3,11,12,14,18,20$ HPV has a well-established role in the development of cervical dysplasia and SCC. HPV 16, 18, 31, and 35, the high-risk HPV types, are strongly associated with SCC. 11 However it is not clear whether PSTCC is associated with HPV infection or not. ${ }^{11,21}$ Koenig et al, Lininger et al and Brink et al showed a positive correlation of PSTCC with HPV 16 infection and a negative correlation with HPV 6,11 , and 18. Their findings support that PSTCC and SCC share a common etiology regarding HPV infection. ${ }^{5,22,23}$ In the present study also, two cases showed cytological evidence of HPV infection which is similar to the findings in a study done by Mani Anand where they also found 3 out of 9 cases showing morphological evidence of HPV infection. ${ }^{9}$ On the contrary, few reports suggest a lower association of HPV with PSTCC as compared to SCC suggesting the role of other etiological factors. Immunostaining with p16 is a surrogate marker to detect HPV infection and can be used to detect precancerous and malignant cervical neoplasms. p16 is never observed in normal cervical epithelium thus, its expression appears to be a specific and sensitive biomarker of cervical neoplasia. ${ }^{19}$ This can be applied to identify the role of HPV in the etiopathogenesis of PSTCC.

The mean age at presentation in the present study is 51.61 years (ranged from 37-62 years) and 16 out of 18 women were postmenopausal. The most common presenting symptom was postmenopausal bleeding in 11 out of 16 cases. Only 2 patients were in the premenopausal age group who presented with postcoital bleeding and metrorrhagia, respectively. In most of the studies, the clinical presentation was elderly lady with postmenopausal bleeding. ${ }^{2,9,10,15,24}$ Other associated symptoms were foulsmelling white discharge, burning micturition, weight loss, and lower abdominal pain similar to the other studies. ${ }^{9,11,19}$ Additionally, abnormal Pap smear was another pathological finding observed by Toshio Fugimoto. ${ }^{11}$

Grossly, PSTCC grows in an exophytic wart-like fashion ${ }^{3,24}$ making it difficult to diagnose invasion on initial/ superficial biopsies. ${ }^{5,12}$ However, the majority of PSTCC cases are found to have an invasion on final histopathology. ${ }^{4,5}$ In the present study 12 cases showed exophytic ulceroproliferative growth and the remaining 6 cases showed ulcero-infiltrative growth.

Microscopically, PSTCC shows a morphological spectrum varying from purely squamous to purely transitional pattern. ${ }^{3}$ Randall et al presented 9 cases of papillary squamous carcinoma of the cervix with detailed morphological analysis, and defined pathologic criteria for diagnosis as follows: moderate to full-thickness dysplastic cells in a papillary architecture with narrow and/ or broad fibrovascular cores resembling HSIL lesion and the invasive component which is usually deep to the papillary excrescences. ${ }^{4}$ Koenig et al diagnosed 32 cases of PSTCC and divided them into 3 groups depending upon predominant histologic features: predominantly squamous $(28.1 \%)$, mixed squamous and transitional (50\%), and transitional (21.9\%). ${ }^{5}$ In the present study we also divided the cases into similar categories. However, all the 18 cases (100\%) showed mixed squamous and transitional features. None of the cases showed pure squamous or pure transitional features. Most of the cases 


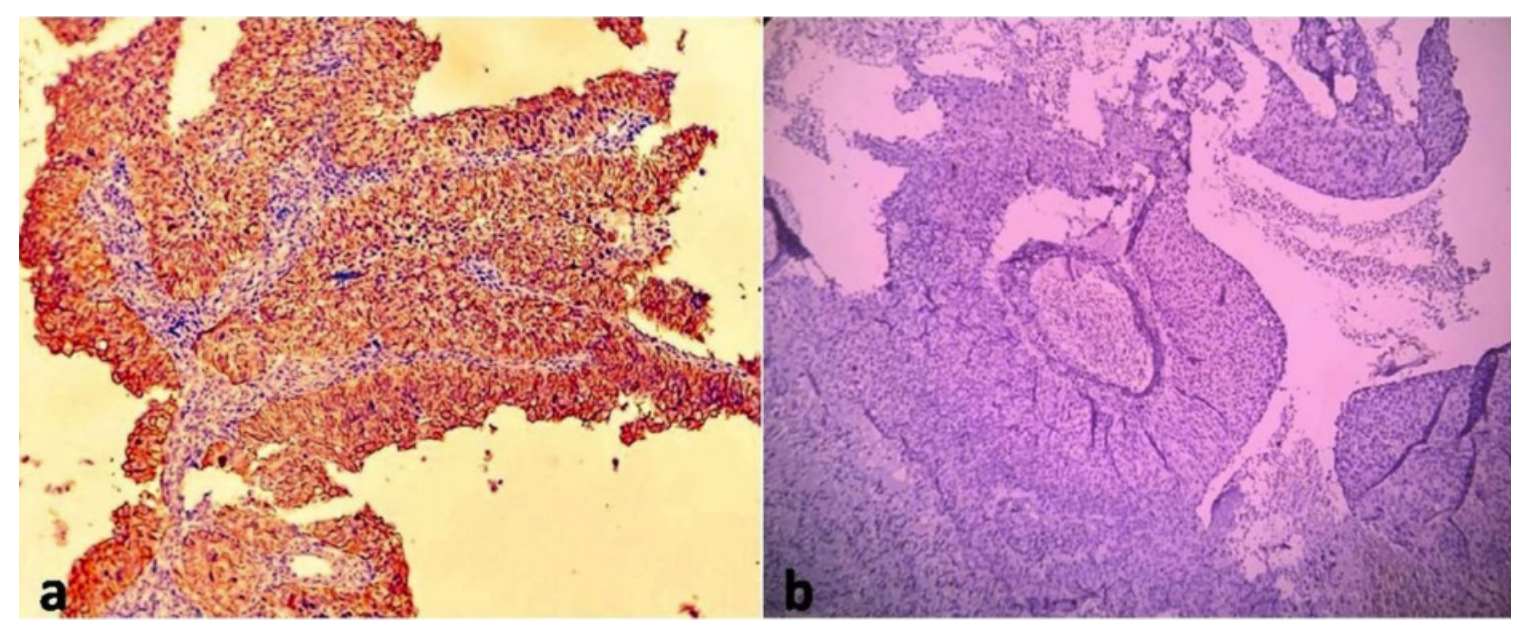

Figure 2: Immunohistochemical staining of tumor cells showing a) Strong cytoplasmic reactivity for CK7 (X200), b) Negative reactivity for $C K 20$ (X200)

in the present study showed papillary architecture with prominent fibrovascular cores similar to observations in the available literature. ${ }^{2-5,8-12,14,15}$ Only 2 cases showed additional micropapillae without any fibrovascular cores similar to the study by Mani Anand. ${ }^{9}$ Three cell types were observed in the present study; intermediate cells (55.5\%), both intermediate and basaloid cells (22.2\%), and intermediate and clear cells $(22.2 \%)$. The presence of intermediate and basaloid cells in PSTCC has also been reported in studies done by Michel Odida, Sunil Jagtap, and Mani Anand.9, ${ }^{94,25}$ Clear cell change has also been reported in two out of 16 cases of PSTCC by Koenig et al and 1 out of 9 cases by Mani Anand et al ${ }^{5,9}$ Evidence of keratinization ranged from $10-35 \%$ of the tumor which is almost similar to the previous studies. ${ }^{3,5,9}$ Many authors described that invasion may be difficult to demonstrate histologically unless deep biopsies are obtained and a high index of suspicion and awareness of this entity should be there to make the diagnosis. 16 out of 18 cases in the present study showed evidence of stromal invasion in the initial biopsy. The remaining 2 cases which were initially reported as HSIL, on repeat punch biopsy were diagnosed as PSTCC showing definitive evidence of stromal invasion. This is in agreement with other studies. ${ }^{2,5}$ The assessment of tumor depth in excision specimen is a difficult task because of the complex surface papillary architecture of these lesions. This can result in incorrect staging which can affect the patient's treatment and prognosis. ${ }^{9}$

IHC profiles were analyzed by various studies to understand the origin of these tumors. ${ }^{2,5,9,10,14,24}$ Most PSTCC display the cytokeratin profile of SCC of the cervix (i.e. $\mathrm{CK} 7+1$ CK20-) in contrast to TCC of the urinary bladder (CK7+/ $\mathrm{CK} 20+) .{ }^{5}$ This was further supported in a study by Moll et al. In their study, one of the cases of SCC of the urinary bladder lacked CK20 expression suggesting that loss of CK20 immunoreactivity was analogous to the loss of classic transitional features, and development of squamous differentiation in transitional cells. ${ }^{26}$ In their series of evaluation of CK7/20 immunohistochemical profile of
TCCs of the female genital tract, Lininger et al studied TCC of endometrium while Soslow et al in their study of TCC of ovary established that all the tumors were CK20 negative and most were CK7 positive. In the latter, the investigators postulated that CK20 is expressed in the terminal stages of differentiation of transitional epithelium and is noted mainly in the superficial cells of the transitional cell carcinomas and umbrella cells in the normal urothelium. For some reason, this terminally differentiated cell population does not occur in genital tract transitional cell tumors. ${ }^{5}$ This finding supports that papillary tumors of the cervix are variants of SCC. In the present study, all the cases were CK7 positive and CK20 negative. Hence, CK7/20 profile is useful in differentiating primary genital tract TCC from a TCC of the urinary tract; strong CK20 positivity would favor a urinary tract origin..$^{5,9,22,26}$ IHC prognostic markers like Ki-67 and p53 also help to distinguish PSTCC from TCC and other borderline papillary lesions of the uterine cervix as well as predict their biological behavior. ${ }^{10}$ Besides $\mathrm{p} 53$, uroplakin III was also used to differentiate PSTCC from TCC of urothelial origin. Positive p53 and negative uroplakin III staining suggests that PSTCC is a variant of SCC favoring Mullerian origin, although showing morphological features of urothelial differentiation. ${ }^{9}$

The National Comprehensive Cancer Network treatment guidelines for cervical cancer do not specifically address PSTCC. However it has been suggested by the experts, that treatment of PSTCC should follow the same treatment guidelines as SCC of the cervix. ${ }^{2,4,5,9,11,12,15,24}$ The differential diagnoses of PSTCC are HSIL with papillary configuration, condyloma, squamous papilloma, TCC, endometrioid adenocarcinoma, papillary serous carcinoma, and well-differentiated villoglandular (papillary) adenocarcinoma. ${ }^{2,9,11,14,24}$ Papillary immature metaplasia (PIM) is a newly described low-grade HPV-associated lesion of the cervix, which shares some histological characteristics with PSTCC like filiform papillae, with immature squamous epithelium retaining the mucus cells on the surface of the papillae and individual cells showing mild nuclear atypia 
and infrequent mitotic figures. In contrast, PSTCC shows narrower and longer fibrovascular cores with more diffuse and marked cytological atypia and pleomorphism. Ki-67 labeling index and mitotic figures also help to distinguish PSTCC from this entity.,

From the cases already reported, it is noticeable that the clinical behavior of PSTCC is similar to that of conventional SCC except for the tendency of PSTCC towards local recurrences and late metastasis, therefore prolonged follow-up is recommended..$^{2,5,9,12,15}$ Koenig et al found a late recurrence of 12 years after initial diagnosis in one patient which was further supported by late recurrence in 2 patients in a study by Randall et al., ${ }^{4,5}$ In the present study also one case showed late recurrence after 10 years of hysterectomy.

\section{CONCLUSIONS}

Papillary squamotransitional cell carcinoma is a rare and distinct histopathological subtype of SCC that deserves accurate biopsy diagnosis. Although clinical history and gross appearance suggest a malignant neoplasm, there are many pitfalls encountered in diagnosing PSTCC. Because of their complex architecture, a superficial biopsy specimen may only show papillary structures without underlying stromal tissue making it difficult to diagnose the invasion. A deep wedge biopsy or conization may be necessary to demonstrate the invasive component which is usually present beneath the papillary excrescences. The presence of bland-looking basaloid cells or high-grade squamous intraepithelial lesion cells may lead to underreporting as HSIL, condyloma, squamous papilloma, or papillary immature metaplasia. The assessment of tumor depth in excision specimens is also a difficult task because of the complex surface papillary architecture of these lesions. This can result in incorrect staging which can affect the patient's treatment and prognosis. Their partial to complete resemblance to urinary tract tumors makes it mandatory to know this entity and differentiate it from metastasis from primary urothelial tract tumors. IHC plays an important role in the diagnosis and prognosis of these tumors and is recommended in every case. Further studies are required to establish its etiological association with HPV infection. Late recurrence and metastasis warrant a longer duration of follow-up in these tumors.

\section{Conflict of interest: None}

\section{REFERENCES}

1. Mc Graw SL, Ferrante JM. Update on prevention and screening of cervical cancer. World J Clin Oncol 2014;4:744-52. Crossref

2. Anusha M, Anuradha P, Praveen MK, et al. Papillary squamotransitional cell carcinoma. Canc Therapy \& Oncol Int J 2018;10:555792. Crossref
3. Kokka F, Verma M, Singh N, et al. Papillary squamotransitional cell carcinoma of the uterine cervix: Report of three cases and review of the literature. Pathology 2006;38: 584-6. Crossref

4. Randall ME, Andersen WA, Mills SE, et al. Papillary squamous cell carcinoma of the uterine cervix: A clinicopathologic study of nine cases. Int J GynecolPathol 1986;5:1-10. Crossref

5. Koenig C, Turnicky RP, Kankam CF, et al. Papillary squamotransitional cell carcinoma of the cervix: A report of 32 cases. Am J Surg Pathol 1997;21:915-21. Crossref

6. Austin RM, Norris HJ. Malignant Brenner tumour and transitional cell carcinoma of the ovary. Int J of Gyn Pathol 1987;6:29-39. Crossref

7. Bass PS, Birch B, Smart C, et al. Low grade transitional cell carcinoma of the vagina-an unusual cause of vaginal bleeding. Histopathology 1994;24:581-3. Crossref

8. Albores SJ, Young RH. Transitional cell neoplasms (carcinomas and inverted papillomas) of the uterine cervix. A report of five cases. Am J Surg Pathol 1995;19:1138-45. rossref

9. Anand M, Deshmukh SD, Gulati HK. Papillary squamotransitional cell carcinoma of the uterine cervix: a histomorphological and immunohistochemical study of nine cases. Indian $\mathrm{J}$ of Med PaediatrOncol 2013;34:66-71. Crossref

10. Kaur M, Goyal N, Dass C, et al. Papillary squamotransitional cell carcinoma cervix- A rare case report. Ann. Int. Med. Den. Res 2018;4:PT15-PT17. Crossref

11. Fujimoto T, Sakuragi N, Shimizu M, et al. Papillary squamous cell carcinoma of the uterine cervix: A report of two cases with human papillomavirus 16 DNA. Acta ObstetGynecolSc 2002;81:176-8. Crossref

12. Turker LB, Gressel GM, Abadi M, et al. Papillary squamous cell carcinoma of the cervix: Two cases and a review of the literature. Gynecol Oncol Rep 2016;18:18-21. Crossref

13. M. Akbar SA, Tunio MA, Al-Dandan S, et al. Papillary squamotransitional cell carcinoma of the uterine cervix : a case report and review of the literature. Case Rep ObstetGynaecol 2016;7107910. Crossref

14. Anant M, Singh A, Singh VY. Papillary squamotransitional cell carcinoma cervix: Case report of a rare variant. J of South Asian Federation ObsGynaecol 2018;10:429-31. Crossref

15. Gitas G, Ertan K, Rody A, et al. Papillary squamotransitional cell carcinoma of the uterine cervix: a case report and review of the literature. J Med Case Rep 2019;13:319. Crossref

16. Woods RSR, Keegan H, White C, et al. Cytokeratin 7 in oropharyngeal 
squamous cell carcinoma: A junctional biomarker for human papilloma virus- related tumors. Cancer Epidemiol Biomarkers Prev 2017;26:702-10. Crossref

17. Marsh MR. Papilloma of the cervix. Am J ObstetGynecol 1952;64:281-91. Crossref

18. Kazal HL, Long JP. Squamous cell papillomas of the uterine cervix; A report of 20 cases. Cancer 1958;11:1049-59. Crossref

19. Priya S, Joseph LD, Rajendiran S, et al. Papillary squamotransitional cell carcinoma of the uterine cervix: A histomorphological and immunohistochemical study of 10 cases. Indian J Pathol Oncol 2017;4:71-6. DOI: 10.18231/2394-6792.2017.0014

20. Wells M, Östör AG, Crum CP. Tumours of the uterine cervix. In: Tavassoli FA, Devilee P, eds. World Health Organization Classification of Tumours. Pathology and Genetics of Tumours of the Breast and Female Genital Organs. 3rd ed. Lyon: IARC, 2003;25989.

21. Ollayos CW, Lichy J, Duncan BW, et al. Papillary squamous cell carcinoma of the uterine cervix: Report of a case with HPV 16 DNA and brief review. Gynecol Oncol 1996;63:388-91. Crossref
22. Lininger RA, Wistuba I, Gazdar A, et al. Human papillomavirus type 16 is detected in transitional cell carcinomas and squamotransitional cell carcinoma of the cervix and endometrium. Cancer 1998;83:5217. Crossref

23. Brinck U, Jakob C, Bau O, et al. Papillary squamous cell carcinoma of the uterine cervix; report of three cases and a review of its classification. Int J GynecolPathol. 2000;19:231-5. Crossref

24. Jagtap SV, Boral S, Kshirsagar N, et al. Papillary squamotransitional cell carcinoma of uterine cervix- an uncommon histopathological variant. Int J Health Sci Res. 2018;8:389-91. Website

25. Odida M. Papillary squamous cell carcinoma of the cervix in Uganda: A report of 20 cases. Afr Health Sci 2005;5:291-4. Website

26. Moll R, Löwe A, Laufer J, et al. Cytokeratin 20 in human carcinomas. A new histodiagnostic marker detected by monoclonal antibodies. Am J Pathol 1992;140:427-47. Crossref 